\title{
Gendered Patterns in Teacher-Student Interaction in EFL Classroom: The Greek Context
}

\author{
Stella Minasyan \\ Aristotle University of Thessaloniki \\ Correspondence concerning this article should be addressed to Stella Minasyan, Aristotle University of \\ Thessaloniki, University Campus, 54124, Thessaloniki, Greece.E-mail: lulushik@yahoo.com
}

\begin{abstract}
The present research endeavours to shed light on the role that gender plays in the language classroom in the Greek context. As no systematic investigation has considered special aspects of gender and interaction in primary school classrooms, this study seeks to investigate how teachers and students position themselves within different discourses in EFL classroom interaction. The issues discussed include turn-taking and interruptions, praise and reprimand, class dominance, teacher attention and class participation in classroom interaction. Drawing on language and gender research, it was hypothesized that gender of the learner affects the learner's language use and behaviour during EFL interaction. This study advances our understanding of gendered classroom interaction and highlights important ways in which students' gender influences teacher-student, as well as student-student interaction. Moreover, this study sheds light on gender bias which occurs in the classroom and thus impedes teachers' abilities to work successfully with all students. The Greek data revealed great similarity with findings of previous studies by supporting the assumption that: (a) teachers are biased in favour of boys, especially with respect to giving them more attention; (b) male students demand more teacher attention and more instructions from the teacher than their female peers; (c) female students are more likely to receive praise and positive comments, whereas male students are reprimanded by the teacher; (d) male students are more active in class participation, by taking more turns, volunteering and calling out.
\end{abstract}

Keywords: gender differences, interaction patterns, gender bias, classroom discourse, difference theory

Owing to a vast and undoubtedly increasing amount of research on gender theories in the language area, the field of language and gender has become 'one of the most lively, sophisticated, and interdisciplinary areas of linguistic inquiry' (Pavlenko \& Piller, 2001, p. 2). One particularly popular question has been the extent to which men and women use language differently. This popularity stems, in part, from the fact that language is an inherently social phenomenon which provides insights into how men's and women's language use can affect their social worlds (Zendedel \& Ebrahimi, 2013).

Due to the fact that language is a social phenomenon, it is strongly influenced by social and cultural factors such as gender, age, educational level, social level and so forth. Discovery of the existing relationship between language and linguistic variations is commonly provided through the examination of linguistic and social differences. The study of gender is important to the study of language and the first step to study gender is to explore the difference between men and women.

Our research deals with classroom interaction, which has always been an interesting and a fruitful subject of study (e.g., Sinclair \& Coulthard, 1975; Mehan, 1979; Drew \& Heritage, 1992; Nassaji \& Wells, 2000; Cazden, 2001; Seedhouse, 2004; Walsh, 2006; Lee, 2007; Constantinou, 2008) because communication in the classroom always differs from communication in a normal social setting. Moreover, when interaction is considered from the point of view of gender in the EFL classroom (e.g. Sunderland, 1992, 1994, 1998, 2000, 2001, 2006; Swann, 1992; Lindroos, 1995; Goddard and Patterson, 2000), it can be extremely fascinating and useful because potential gender differences influence 
the academic and social lives of students.

Through this exploration, we hope to make a substantial contribution to the field of research on gender bias in the EFL classroom by uncovering several findings with important implications for our understanding of gendered classroom interaction and by highlighting important ways in which gender influences teacher-student, as well as student-student interaction, in Greek primary schools. Therefore, this study is up-to-date, practical and claims to offer benefits to the emerging research on classroom interaction.

The study was undertaken in order to investigate and to reveal whether there are any correlations between gender and linguistic behaviour of fifth grade learners. Qualitative research was considered appropriate for this study in the particular EFL classroom setting as far as it occurs in natural settings where human behaviour and events occur.

\section{Materials}

There are three main theoretical approaches within language and gender studies: dominance theory, difference theory and diversity theory (Cameron, 2005). Dominance theory emphasized how growing up in a patriarchal society essentially predisposed females as subordinates and males as the dominant group and set out to explore how this unequal social arrangement was both reflected in, and reinforced by, language (Cameron, 2005).

Difference theory, on the other hand, broke away from concentrating on male's domination over women and ascribed gender differences in speech to the distinct socialization patterns of girls and boys (Cameron, 2005). It has been observed that girls and boys prefer to spend their time with same-sex children from a very early age (Eckert \& McConnellGinet, 2003). This same-sex preference observed in playgroup and friendship formation brings about two distinct subcultures of males and females, each of which develops its own group norms and practices (Tannen, 2001). Girls' groups are built on cooperation, whereas boys' groups are greater in size and display a hierarchical organization, and these differences manifest in language use as well (Tannen, 2001). The difference approach rejects the idea that everything women say reflects their lack of power and confidence (Cameron, 2005).

The third theoretical approach within the study of language and gender is diversity theory, which radically differs from the previous two in several ways. First, it questions the distinction of sex and gender, claiming that similarly to gender, sex is a social construct as well (Cameron, 2005). Second, it problematizes the practice of handling men and women as two distinct but internally uniform groups (Cameron, 2005). Consequently, the emphasis is put on revealing the many types of existing gender identities and sexualities.

Our study will adopt the difference theory approach because our research has taken place in classrooms. Within the classroom, students have equal rights and opportunities: therefore, gender differences cannot be interpreted as reflections of a hierarchy that positions male students as dominating over females. Moreover, the dual categorization of students as male and female is usually the most that is done in the area of learner differences (Chavez, 2001). This ignores the diversity theory's claim that considering gender as a binary category is problematic. Therefore, we will use the category of gender as distinguishing two groups, male and female, whose linguistic behaviour displays systematic differences that are worth investigating.

\section{Methods}

The main goal of this study is to fill a gap in the research of gender in the language classroom in the Greek context by investigating and determining whether the gender of the learner affects the learner's language use and behavior during EFL classroom interaction in primary schools in Greece, particularly in the city of Thessaloniki. The study looked at the various interaction patterns in each of the classrooms, and whether teachers used different patterns with children based on their gender. Through this exploration, we hope to make substantial contribution to the field of research on gender bias in the EFL classroom by uncovering several findings with important implications for our understanding of gendered classroom interaction and by highlighting important ways in which gender influences teacherstudent, as well as student-student interaction, in Greek primary schools. Therefore, this study is upto-date, practical and claims to offer benefits to the emerging research on classroom interaction.

Based on the purpose of the study, the following questions were used to guide the research:

Research question 1: Are there any gender differences as far as class turn taking and interruptions are concerned?

Research question 2: Are there any gender differences in receiving praise and positive comments?

Research question 3: Are there any gender differences in getting blame and reprimand from the teacher?

Research question 4: Are there any gender 
differences with regard to student dominance in EFL classroom interaction?

Research question 5: Are there any gender differences with respect to demanding and getting more teacher attention?

Research question 6: Are there any gender differences regarding class participation during EFL classroom interaction?

\section{Research Participants}

In order to achieve more generalizable results, it was considered necessary to carry out the study in as many schools as possible. An adequate range of sampling was, consequently, needed which could provide enough data to allow us to draw evidential conclusions. A sample of 81 students and 70 teachers was selected, aiming at collecting enough data to reach generalizable conclusions. Students from four different classes participated in the study, all of them fifth graders. The particular age was chosen as students at that age have already been exposed to EFL for at least three years and thus had attained quite a good level of English.

All teacher participants were Greek who taught English as a foreign language, with ages that ranged between 30 to 45 years. All the participants were informed about the purpose of the researcher's presence in the classroom (though not the exact research area of our study) and all of them agreed to be observed. They were told that mainly teacherstudent interaction patterns would be observed during their classes, but not specifically gender differences in these patterns. Participant information was kept anonymous in order to respect the personal beliefs of the participants as well as to ensure confidentiality of the data (Creswell \& Clark, 2007).

\section{Procedure}

The questionnaire was selected as a useful research instrument because, although it is time-consuming and labour-intensive in design and analysis, it exhibits several advantages. First, the responses are collected in a standardized way, so questionnaires are more objective, certainly more so than interviews (Milne, 1999). Second, information can be collected from a large sample. Moreover, they are simple to administer, they should be simple and quick for the respondent to complete and they are usually straightforward to analyse. Furthermore, data entry and tabulation for nearly all surveys can be easily done by using software packages. The questionnaire was designed to elicit data in relation to the extent, pattern and nature of gender differences in language use and behaviour in classroom and classroom interaction in general.
To this aim, the questionnaire was divided into two parts: Part I elicited demographic information and Part II provided information on gender and linguistic behaviour of students. The questionnaire was administered in English, as it was the language of instruction in the EFL classes used as research settings. It consisted of 23 items of which 10 were Yes/ No question items and 12 items were multiple choice questions with four choices (male, female, both and no answer). The questionnaire template designed for this study is given in the Appendix. All questionnaire items aimed to elicit respondents' opinion and attitudes to main gender issues. Only one open-ended item was employed which sought to elicit comments and remarks related to gender issues in EFL class.

\section{Results and Discussion}

Based on the results of our study, it can be concluded that female students are at a disadvantage in the foreign language classroom by receiving less attention from the teacher than that given to boys. In the early work in this area, Brophy \& Good (1970) observed that boys have more interactions with the teacher than girls and appear to be generally more salient in the teacher's perceptual field. This gender imbalance has led to some relatively extreme claims, especially by writers approaching the issue from a feminist perspective. Perhaps the best-known work in this tradition is that of Spender, who writes of boys receiving, "[s]o much more attention from teacher than do girls" (Spender, 1982, p. 54). Spender also claims that gender imbalances are so routinized and expected in classrooms that even when teachers are trying to equalize attention, girls get only just over a third of the teacher's time (Spender, 1982).

With regards to gender differences in turn-taking, the findings suggest that male students take more turns in classroom interaction, and as to the frequency of interruptions, male students interrupted more frequently in teacher-student interaction as well as in peer interaction, which confirms previous findings (Holmes, 1995; Chavez, 2001).

However, the significant gender difference in the present study does not lie in the frequency but rather in the functions of interruptions. The notion that women behave cooperatively in conversations as opposed to men's competitiveness (Tannen, 2001) has been confirmed by the functions for which male and female students used interruptions. Regarding the gender difference in cooperative interruptions, an interesting result found in the present study is that female students used interruptions mainly for cooperative reasons, such as providing assistance 
or expressing agreement, whereas male students interrupted intrusively with the aim to gain the speaking floor or to express disagreement. Moreover, another interesting result is that the interruptions are more frequently initiated between opposite-sex speakers than between same-sex speakers, which had not been seen in previous work. Most of the cooperative interruptions were instances of mistimed (either early or late) answers to the teacher's questions. The following excerpts illustrate a mistimed answer:

Excerpt 1

M1: (reading) The criminal which was arrested had robbed a bank.

$\mathrm{T}$ : The criminal

M2: //O $\chi 1$ which, who $\pi \rho \varepsilon ́ \pi \varepsilon \imath$ v $\alpha$ val. (It is not which, it should be who.)

T: Tí cívar criminal? (What does criminal mean?)

M1: $\varepsilon \gamma \kappa \lambda \eta \mu \alpha \tau i \alpha \varsigma$ (criminal)

T: So ...

M1: The criminal who was arrested had robbed a bank.

Excerpt 2

$\mathrm{T}$ : Look, there is a difference between travel and trip. What does travel mean? Travel means

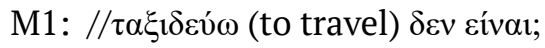

M2: //Should we hand the copies now?

$\mathrm{T}$ : Wait a moment, please, George!

In these excerpts we can see that the teacher's question is not immediately followed by an answer and the first answer only arrives when she already goes on to answer her own question. Consequently, the teacher is interrupted. Tannen (1983 and later work) proves that interruption can have a cooperative function, which is considered to be a way of indicating that one is interested in, enthusiastic about, and highly involved in the conversation Here, in these excerpts, mistimed answers are categorized as cooperative interruptions, because replying to the teacher's question signals a student's involvement and cooperation in interacting with the teacher, regardless of whether the reply arrives early or late. In this sense, the mistimed answers are similar to what $\mathrm{Li}$ (2001) calls 'assistance interruptions', which are aimed at helping the current speaker who is in need of either a word or an idea. Of course, the kind of assistance the teacher needs is not in connection to language problems but rather to the smooth flow of the lesson for which student cooperation is essential.

Besides cooperative interruptions, there are instances when students started talking without the teacher explicitly asking or expecting them to do so, therefore these instances are categorized as intrusive interruptions. The following excerpts from our data are examples of intrusive interruptions:
Excerpt 3

T: So, you will have Exercise $3,4,7 \ldots \ldots$. and 8 for home

M1: //Look, Exercise 3 is on prepositions. We put in, on, at, under.

T: Yes, exactly.

M1: And we have to match sentences

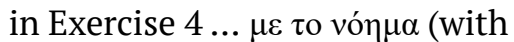
meaning).

T: Yes, thank you.

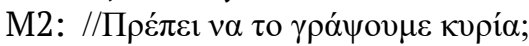
(Should we write them down?)

T: No, we are going to do it orally. Have you written them down in your copy?

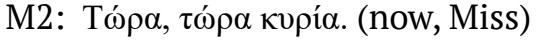

Excerpt 4

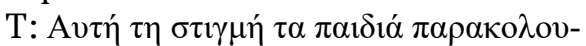
Өov́v $\tau \eta \lambda \varepsilon$ $\rho \alpha \sigma \eta$. (The children are watching TV now.)

M1: The children are watching TV now.

M2: Yes, we use watching, not looking,

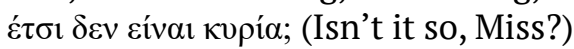

T: Exactly.

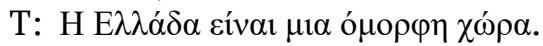

F: Greece is a very beautiful $\chi \omega \dot{\omega} \rho \alpha$ (country).

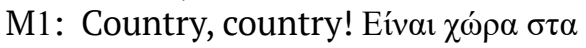
$\alpha \gamma \gamma \lambda \iota \kappa \alpha ́$. (It's country in English.)

M2: $\Gamma \alpha \lambda \lambda i \alpha$ (France) is also beautiful.

T: country. Correct!

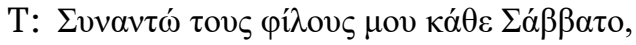

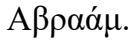

M3: I meet my friends every Sunday,

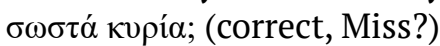

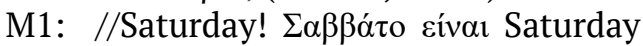
$\sigma \tau \alpha \alpha \gamma \gamma \lambda ı$ «ó. (It is Saturday in English.)

In excerpts 3 and 4, M1, M2 and M3 do not change the topic the teacher starts talking about, neither do they disagree, so their interruption qualifies as a floor-taking interruption, with the intent 'to obtain the conversational floor' (Murata, 1994, p. 389). The teacher's positive feedback 'yes, exactly, correct', which acknowledges M1's knowledge of prepositions in excerpt 3 and M1's and M2's knowledge of foreign words in excerpt 4 , denotes that student contributions to classroom talk are highly valued, even if they are interruptive. In excerpt 4 we have a kind of interruption that is not related to opposition, instead it is primarily supportive and collaborative in nature. For example, according to James \& Clarke (1993, p. 239), Edelsky (1981) finds that interruption is a signal of a high degree of involvement in conversation or task performance. Participants interrupt each other and talk simultaneously to develop an idea together and produce a joint answer to a question. The present study focused also on the interaction between the 
teacher and both male and female students in terms of providing approval or disapproval (i.e. positive and negative feedback). In terms of the research question as to in what way the teacher reacts and gives feedback to her students' responses, some interesting conclusions can be made. The teachers used praise and reprimands in response to students' academic behavior regardless of the gender of the student, whereas in response to student's classroom social behavior they mostly used reprimands, usually addressed to male students.

Excerpt 5

T: (to a boy) I was going to give you a grade for participation. Where is your participation? It's going to drop.

M: But I speak good English. Wait a second! Don't clean the blackboard.

$\mathrm{T}$ : Ok, complete the sentence using Present Continuous Tense.

M: John is on the ladder. He is holding on with his hands.

T: Great! Good job!

Excerpt 6

T: Exericise A is to match the beginning of the sentence on the left with the correct ending on the rignt. E $\lambda \dot{\varepsilon} v \eta$,

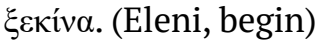

G: (reading) When I grow up I really want to (pause)

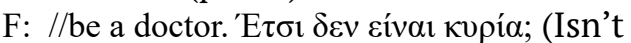
it so, Miss?)

T: Yes, exactly, very good! Manoli, take out your book, otherwise you will leave the classroom!

M: $\Theta \varepsilon ́ \lambda \omega v \alpha \mu \varepsilon i v \omega$ ! (I want to stay)

$\mathrm{T}$ : Ok, then read the next sentence.

M: (reading) Flying in a plane (pause) makes me feel nervous.

T: You are great! Good for you!

It is obvious in the excerpts illustrated above that in response to students' academic behaviour in excerpts 5 and 6 when male students provide grammatically correct sentences, teachers used praise statements ('Great', Good job', 'You are great', 'Good for you') and not disapproving comments, whereas in response to students' classroom social behavior they used reprimands ('Your participation is going to drop!', 'Take out your book, otherwise you will leave the classroom!'). In excerpt 5 , the teacher's reprimand is in the form of a warning, that the student's grade for participation is going to drop and in excerpt 6 the teacher warns the student that if he does not behave properly in class, he will leave the classroom.

Regarding the interaction between the teacher and the students, significant differences are found in teachers' reactions to male and female students' responses in the classroom. Teachers seem to be in favor of female students especially in respect of encouraging them more and giving them more positive feedback as shown in the excerpt 7 . This can be attributed to the fact that girls are more reluctant to speak, they are less confident, and thus experience what the literature calls "loss of voice" (Brown \& Gilligan, 1992; Orenstein, 1994). This form of interaction between the teacher and the student is a key element in our research since the more the teacher addresses the student, the more involved the learner becomes and, according to Dornyei (2001), the more the student is required to become an active participant of an activity, the more likely he or she finds the learning situation stimulating, which is one of the most important issues in successful language learning.

Excerpt 7

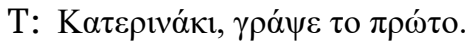
(Katerinaki, write the first one.)

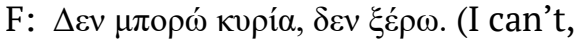
Miss. I don't know.)

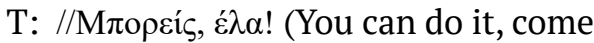
on!) It is not difficult at all.

F: (writing on the blackboard) You are not allowed to smoke on this airplane.

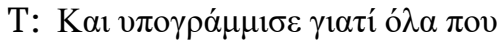

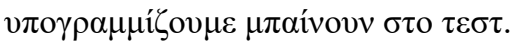

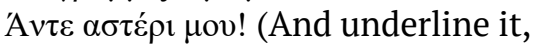
because everything we underline will be in the test. Come on, my star!)

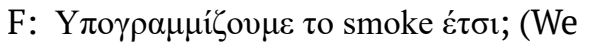
underline to smoke, don't we?)

T: Yes, exactly! Well done! A very good job!

In the feedback in excerpt 7 the teacher does not accept the female student's self-criticism about her skills and abilities. Instead, she encourages her to complete the task, claiming that it is not difficult at all and that she can do it. Such behavior is expected to boost students' academic involvement in classroom interaction.

Furthermore, findings of our study suggest that male students are more likely than female students to be reprimanded during EFL classroom interaction for their inappropriate behaviour as shown below and this is in accordance with empirical evidence throughout the research literature (Wing, 1997; Younger et al., 1999; Francis, 2000; Jones \& Dinda, 2004).

Excerpt 8

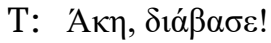

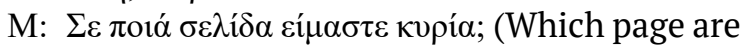
we on, Miss?)

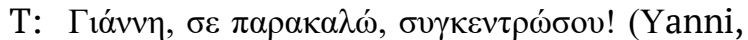

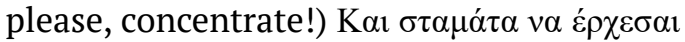

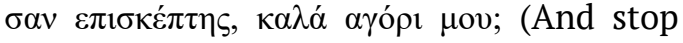
coming in like a visitor, ok my boy?) 


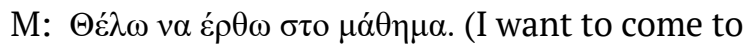
class.)

Another important focus of the current study is the examination of gender differences with regards to student dominance in interaction. Based on the findings of the observations in four classes, it was concluded that male students dominate the class more than their female peers.

Excerpt 9

$\mathrm{T}$ : Daddy is shopping and

M1: and buy some new dresses

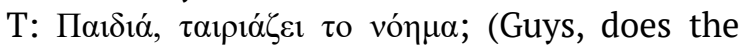
meaning match?)

M2: Nal, val, кvpía. (Yes, yes, Miss)

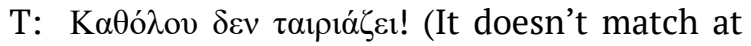

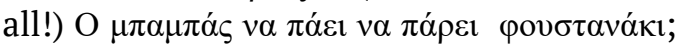
(Daddy to go and buy a dress?)

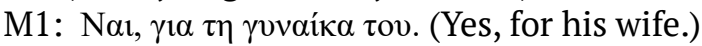

M3: for his wife, Miss.

On the whole, our results corroborate findings of previous studies, which show that in the discourse of Greek adults as well as in classroom discourse, women are dominated by men (Altani, 1992; Pavlidou, 1999; Makri-Tsilipakou, 2002). Girls' cooperative behavior is also observed in the classroom setting by Archakis (1992), who found that girls interrupt the teacher less often than boys, but also that most of the girls' interruptions are cooperative, whereas most of the boys' intrusions are of the dominant kind. Our analysis of interactions in EFL classroom, as in Archakis' (1992), yielded that girls participate to a lesser extent in dialogues with the teacher, but also they develop less verbal initiative in class than boys. For the most part, as our findings show, the negotiation of positions of power in teacher-student interactions is related to the gender of the students. Male students in the conversational episodes of these data exhibit a strong tendency to preserve their independence, resisting female students' efforts to dominate both the exchanges and the activities.

The study also sought to find out whether male and female students demand and receive differential teacher attention in class. Our findings corroborate those of previous studies (Brophy \& Good, 1970; Stanworth, 1981; French \& French, 1984; Sadker \& Sadker, 1994; Younger et al., 1999; Duffy et al., 2001; Tsouroufli, 2002; Swinson \& Knight, 2007) by supporting the assumption that male students tend to ask more questions in class and are more likely to offer contributions to discussion. As a result, they receive more attention from the teacher and are addressed more often regardless of whether they raise their hand, as seen in the example below. Some possible explanations for this might be that boys tend to be more active and willing to speak, and that they are not afraid of takings risks when it comes to speaking.
Moreover, the need for disciplining male students seems relevant as well, which might contribute to boys having more chances to speak and get attention.

Excerpt 10

$\mathrm{T}$ : Please, sit properly and get ready for the lesson. Alex, you too, turn around and get ready.

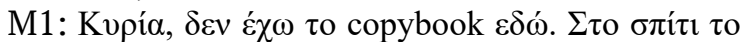
$\varepsilon \chi \omega$. (Miss, I don't have my copybook here. I have it at home.)

$\mathrm{T}$ : Have a look, maybe it's there.

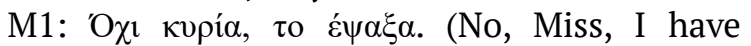
searched for it.)

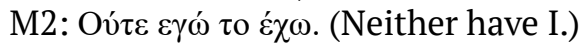

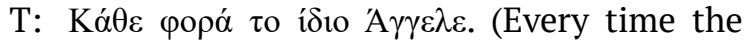
same situation Aggele.)

F: Can I read, Miss?

$\mathrm{T}$ : Yes, please, Maria.

Furthermore, it should be pointed out that the teachers in our study seem to be unaware of the fact that they pay more attention to male students. Thus, while we acknowledge that teacher bias can be responsible for more attention being provided to males, we can assert that "remediation of male biased teacher attention" (French \& French, 1984) alone may not be sufficient to achieve a change in interactional bias favoring male students. As French \& French (1984) state, teachers must also become sensitive to the interactional methods used by students themselves (in this case largely boys) in, "securing attention and conversational engagement", and that in the main the strategies female students use remain 'invisible' to teachers (p.133).

In addition, this study provided valuable insights on whether class participation on the whole is gender differentiated in classroom interaction. In our study we find a clear trend: male students participate in classes more than females do and the results are in line with previous works (Brooks, 1982; Wingate, 1984; O’Keefe, 1987; Banks, 1988; Crawford, 1990).

Excerpt 11

$\mathrm{T}$ : Now please, Maria, complete the passage with the correct form of the verb in brackets, using the causative form of the verb, ok?

F: King George had the outside of the Palace (design) designed in Indian style and he had the inside (decorate) decorated in Chinese style.

T: Ok.

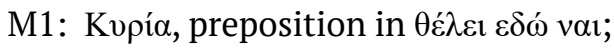
(Miss, it requires preposition in here, doesn't it?)

$\mathrm{T}$ : Yes! You are very attentive. Repeat, please. In

M1://in Chinese style 
M2: $\varepsilon \pi i ́ \sigma \eta \varsigma$ (also) in Indian style

T: Correct.

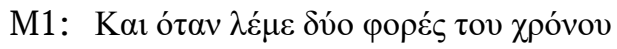
$\lambda \varepsilon \dot{\mu} \mu \varepsilon$ twice a year, not twice in a year,

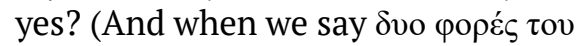

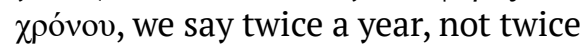
in a year, yes?)

T: Exactly.

Moreover, findings of the present study indicate that teacher's choice of which student will participate is gender differentiated and favors male students.

Excerpt 13

T: What's a wheel? You, please, Leonidas.

M1: Eүَ́, кvрía; (Me, Miss?)

$\mathrm{T}$ : Yes, you, please.

M1: pó $\delta \alpha$ (wheel)

T: Could you please repeat what you said and its equivalent in English?

M1: pó $\alpha \alpha$ cíval (is) wheel

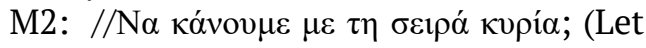
us do it in turns, Miss).

$\mathrm{T}$ : Yes, please.

M2: They never stay at the same town for more than a week.

T: So, what time expression do we use here? And what other time expressions do we know with Present Simple?

M2: We have never here. We also know sometimes, always, often.

$\mathrm{T}$ : Thank you, one more please.

M1: Sorry?

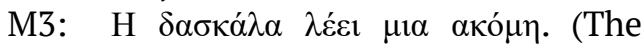
teacher says one more.)

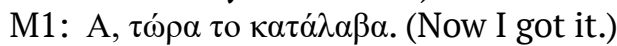

These findings support the results of studies by Sadker \& Sadker (1985) and Swann \& Graddol (1988). Interestingly enough, questionnaire data do not indicate statistically significant gender differences regarding students' class participation, showing that teachers' treatment toward male and female students is not gender specified. Nevertheless, the observations suggest that this is not the case. Teacher respondents during our observations are biased in favor of male students when they select students for class participation. These findings are in accordance with the views of Constantinou (2008), who reported that "the overall ratio of teacher-student interaction favored males" (p. 29).

\section{Limitations}

Although the findings of this study contribute to research in gender bias in the EFL classroom, certain limitations should be pointed out. Due to the limited number of students and teachers compared with the total number of students and teachers in Greece, their views and opinions as well as the limited nature of the data (as for example the lack of videotaped data), the sample cannot be considered illustrative of the whole Greek primary school pupils' and teachers' community. However, the themes identified in the present study, and particularly the problems brought forward by the respondents as regards to gender differences in EFL classroom interaction, can outline some general matters of concern on gender issues in classroom interaction. In addition, they can definitely point towards certain directions and serve as helpful tools for other primary school teachers in Greece.

Moreover, the data for the present study is too narrow to allow us to draw any definite conclusions about differences in teachers' reactions to student's responses according to their gender, or to generalize teachers' negative behavior towards all male students. Furthermore, the preponderance of female teachers in elementary schools and the lack of male teachers especially in the early grades is by no means an issue only with this particular data set and remains a challenge to this field of research.

Despite its shortcomings, this study holds potential to fill an important gap in the current empirical knowledge concerning Greek state primary school students and language teachers' gendered behavior.

\section{Conclusion}

It is hoped that by investigating such important issues as turn-taking and interruptions, praise and reprimand, class dominance, teacher attention and class participation in classroom interaction, the present study contributed to raising teachers' and researchers' awareness of the importance of gendered behavior. It is suggested that our findings might help teacher training and teacher education programs, as these data and observations might inform the content of those courses.

While answering some important questions, this study introduced some new queries that need to be addressed in future research.

First, future studies should continue to explore the influence of teacher gender on interaction and relationship quality. An issue worth exploring would be a comparative study between male teachers' responses to the questionnaire and female teachers' responses.

Another recommendation is to conduct research on the perceptions of both male and female teachers regarding their attitudes to their students during EFL classroom discourse. Moreover, teachers need to 
examine their own biases in order to best accommodate the needs of boys and girls and help all pupils reach their highest potential at school.

While not the focus of this particular study, potential future research may be carried out by expanding the sample to secondary school teachers, broadening the sample to include other content areas, attaining a better understanding of gender differences in the Greek classroom reality.

Furthermore, the Ministry of Education should provide training programs for teachers aiming to emphasize the importance of gender issues and raise awareness of educators regarding gender biases in classroom interaction. Such knowledge will help teachers improve their relationship with their students.

\section{References}

Brophy,J., \& Good,T.(1970).Teachers' communications of differential expectations for children's classroom performance: Some behavioral data. Journal of Educational Psychology, 61(5), 365-374.

Brown, M., \& Gilligan, C. (1992). Meeting at the crossroads: Women's psychology and girls' development. Cambridge, UK: Harvard University Press.

Cameron, D. (2005). Language, gender, and sexuality: Current issues and new directions. Applied Linguistics, 26, 482-502.

Chavez, M. (2001). Gender in the language classroom. Boston, MA: McGraw-Hill.

Constantinou, P. (2008). Heightening our awareness of gender stereotypes. Strategies: A Journal for Physical and Sport Educators, 21(3), 28-34.

Creswell, W., \& Clark, L. (2007). Designing and conducting mixed method research. Thousand Oaks, CA: Sage Publications.

Dörnyei, Z. (2001). Motivational strategies in the language classroom. Cambridge, UK: Cambridge University Press.
Eckert, P., \& McConnell-Ginet, S. (2003). Language and gender. Cambridge, UK: Cambridge University Press.

Edelsky, C. (1981). Who's got the floor? Language in Society, 10, 383-421.

French, J., \& French, P. (1984). Gender imbalance in the primary classroom: An interactional account. Educational Research, 26, 127-136.

Holmes, J. (1995). Women, men and politeness. New York, NY: Longman.

James, D., \& Clarke, S. (1993). Women, men, and interruptions: A critical review. In D. Tannen (Ed.), Gender and conversational interaction (pp. 231-280). New York, NY: Oxford University Press.

$\mathrm{Li}$, Z. (2001). Cooperative and intrusive interruptions in inter- and intercultural dyadic discourse. Journal of Language and Social Psychology, 20, 259-284.

Milne, J. (1999). Questionnaires: Advantages and disadvantages. In Evaluation cookbook. Edinburgh, Scotland: LTDI Publications.

Murata, K. (1994). Intrusive or co-operative: A crosscultural study of interruption. Journal of Pragmatics, $21,385-400$.

Orenstein, P. (1994). School girls: Young women, selfesteem, and the confidence gap. New York, NY: Doubleday.

Pavlenko, A., Blackledge, A., Piller, I., \& TeutschDwyer, M. (2001). Multilingualism, second language learning and gender. Berlin, Germany: Mouton de Gruyter.

Sadker, D., \& Sadker, M. (1985). Failing at fairness: How our schools cheat girls. New York, NY: Macmillan Publishing Company.

Spender, D. (1982). Invisible women: The schooling scandal. London, UK: Women's Press.

Swann, J., \& Graddol, D. (1988). Gender inequalities in classroom talk. English in Education, 22(1), 48-65.

Tannen, D. (2001). You just don't understand. New York, NY: HarperCollins Publishers Inc.

Zendedel, A., \& Ebrahimi, S. (2013). Gender differences in language use and analysis of Simin Daneshvar's Savushun. European Scientific Journal, 9, 181-189. 


\section{APPENDIX A}

\section{TEACHER QUESTIONNAIRE}

The classroom is a place where inequalities between male and female students can be explored and challenged. Thus, my research deals with gendered patterns in teacher-student interaction in EFL classroom in Greek context.

I am particularly interested in the special insights, perceptions and experiences you have had on patterns of gender differences in teacher-student interactions.

Although the questions lead you in certain directions, please feel free to add ideas you think might be especially relevant from your point of view. Hope you will also find this occasion insightful or rewarding for yourself as well!!!

1. Who takes more turns (in the form of requests, disagreement, etc.) in your class?

$\mathrm{M} \square$

$\mathrm{F} \square$

Both $\square$

Neither $\square$

2. Who interrupts you more often in class?

$\mathrm{M} \square$

$\mathrm{F} \square$

Both $\square$

Neither $\square$

3. Who initiates more interactions with the teacher in your class?

$\begin{array}{lr}\mathrm{M} \square & \text { Both } \square \\ \mathrm{F} \square & \text { Neither } \square\end{array}$

4. Who produces gender stereotypes in your class?

$\begin{array}{lr}\mathrm{M} \square & \text { Both } \square \\ \mathrm{F} \square & \text { Neither } \square\end{array}$

5. Who do you have more instructional exchanges with in your class?
$\mathrm{M} \square$
Both $\square$
$\mathrm{F} \square$
Neither $\square$

6. Who gets more blame, disapproval from your part?

$\mathrm{M} \square$

Both $\square$

$\mathrm{F} \square$

Neither $\square$

7. Who dominates the classroom interaction time?
$\mathrm{M} \square$
Both $\square$
$\mathrm{F} \square$
Neither $\square$

8. Do you have a classroom monopoliser in your class?

Yes $\square$

No $\square$

9. Who do you give more power, space to talk in your class?

$\mathrm{M} \square$

$\mathrm{F} \square$

Both $\square$

Neither $\square$
10. Who demands and gets more teacher attention?
$\mathrm{M} \square$
Both $\square$
$\mathrm{F} \square$
Neither $\square$

11. Are there any gender differences in nonverbal behaviour in class?

Yes $\square$

No $\square$

12. Regarding teacher-initiated feedback who do you give more praise/positive comments?

$\begin{array}{lr}\mathrm{M} \square & \text { Both } \square \\ \mathrm{F} \square & \text { Neither }\end{array}$

13. Do you select your students for class participation based on their gender?

Yes $\square$

No $\square$

14. Who receives more attention from you in your class?
$\mathrm{M} \square$
Both $\square$

$\mathrm{F} \square$

Neither $\square$

15. Who is better at learning English as a second language (producing correct linguistic forms in FL, verbal superiority in FL acquisition)?

$\mathrm{M} \square$

Both $\square$

$\mathrm{F}$ 口

Neither $\square$

16. Do male and female students have different attitudes toward FL learning activities Yes $\square$ (speaking, reading, writing and listening)?

No $\square$

17. Are there any events in your classroom regarding gender differences that you think are attributable to the fact that you are male/ female?

Yes $\square$

No $\square$ 
18. Has your attitude towards male/female students changed over the years?

Yes $\square$

No $\square$

19. Have you ever encountered gender discrimination in class from your students?

Yes $\square$

No $\square$

20. Do you use specific sitting arrangement for your male and female students in your class when they do pairwork or groupwork?

Yes $\square$

No $\square$

21. Do you have fixed ideas on gendered behaviour? Yes $\square$

No $\square$
22. Some teachers report having management problems (e.g. overt disruption, challenging competence, lack of student participation, etc.). Have you had these because you are male/ female?

Yes $\square$

No $\square$

23. Please add any comments/remarks related to the topic of my research. 